\title{
Análisis económico de los costos de producción bajo la influencia del cambio climático en la industria bananera de la Provincia de El Oro
}

\section{Economic analysis of production costs under the influence of climate change in the banana industry of the Province of El Oro}

\author{
Verónica Valeria Castro Tamayo \\ vcastrot@psg.ucacue.edu.ec \\ Universidad Católica de Cuenca, Cuenca \\ Ecuador \\ https://orcid.org/0000-0001-6293-2864 \\ Cecilia Ivonne Narváez Zurita \\ inarvaez@ucacue.edu.ec \\ Universidad Católica de Cuenca, Cuenca \\ Ecuador \\ https://orcid.org/0000-0002-7437-9880 \\ Juan Carlos Erazo Álvarez \\ jcerazo@ucacue.edu.ec \\ Universidad Católica de Cuenca, Cuenca \\ Ecuador \\ https://orcid.org/0000-0001-6480-2270
}

Recibido: 07 de septiembre de 2019

Aprobado: 28 de septiembre de 2019

\section{RESUMEN}

Una de las mayores preocupaciones a nivel mundial es la influencia del calentamiento global y por lo tanto el cambio climático en los diferentes sectores económicos especialmente en los países en vías de desarrollo. El cambio climático está generando variaciones en las formas tradicionales de producir en la agricultura, al alterar las temperaturas, los ciclos de cultivo y cosechas también cambian y estos efectos conllevan a un aumento de los costos de producción. La industria bananera es una de las primordiales fuentes de ingresos para la economía del Ecuador, y la provincia de El Oro es una de las principales 


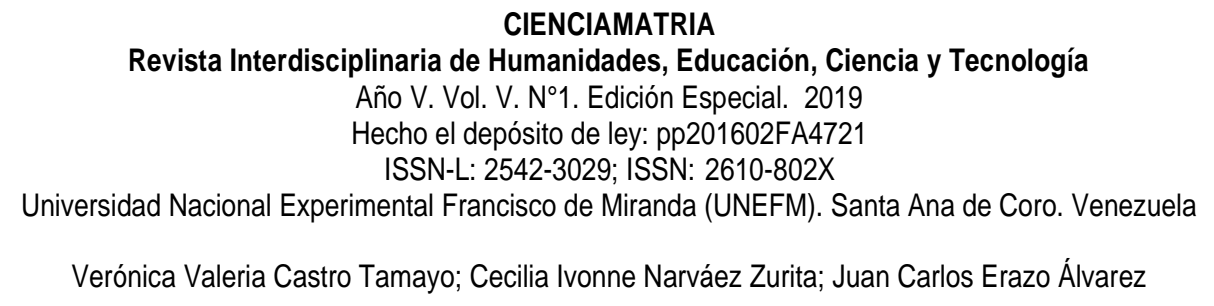

provincias productoras de banano. Con este antecedente, la presente investigación tiene como objetivo efectuar un análisis de la gestión de costos de producción a consecuencia del cambio climático en la industria bananera de la provincia de El Oro y su incidencia en la rentabilidad.

Descriptores: Costos de producción; Análisis económico; Rentabilidad; Cambio climático, Industria bananera.

\begin{abstract}
One of the biggest concerns worldwide is the influence of global warming and therefore climate change in different economic sectors, especially in developing countries. Climate change is generating alterations in traditional ways of producing in agriculture, by altering temperatures, crop cycles and harvests also change and these effects lead to an increase in production costs. The banana industry is one of the main sources of income for the economy of Ecuador, and the province of El Oro is one of the main banana producing provinces. With this background, this research aims to carry out an analysis of production cost management as a result of climate change in the banana industry of the province of El Oro and its impact on profitability.
\end{abstract}

Descriptors: Production costs; Economic analysis; Banana producers; Climate change; Banana industry.

\title{
INTRODUCCIÓN
}

El análisis económico y financiero consiste en la aplicación de un conjunto de técnicas a los diferentes estados financieros con el objetivo de diagnosticar la situación de una empresa y con fundamentos tomar decisiones para resolver los problemas detectados, mantener aspectos positivos y preparar la marcha de la empresa.

Los costos de producción constituyen el efectivo que se sacrifica para obtener bienes y servicios que se espera que aporten un beneficio actual o futuro para la organización (Cárdenas y Nápoles, 2016). Por lo cual, un análisis de la gestión de costos de producción permite tener un mejor manejo de costos, programar y optimizar recursos disponibles y así mejorar la rentabilidad de los mismos. 


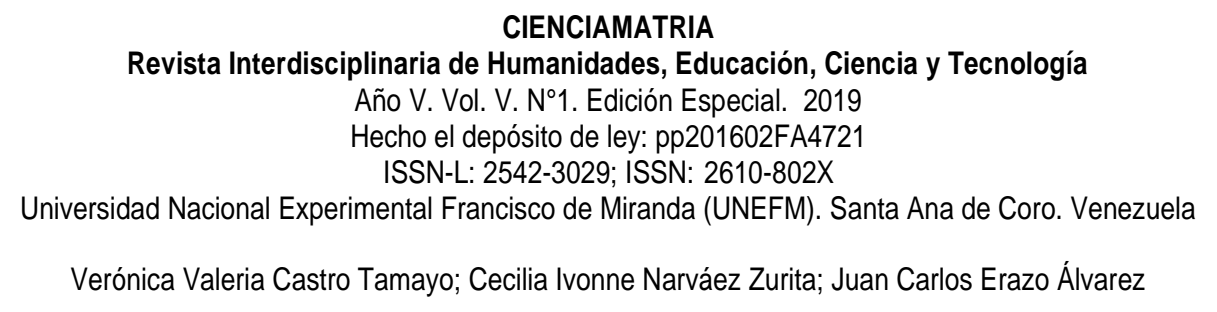

Investigar el sector de la industria del banano es indagar en uno de los recursos más importantes que impulsa el desarrollo económico del Ecuador. La producción y exportación bananera han ido creciendo paulatinamente a pesar que el sector tiene que sobrellevar difíciles etapas por las consecuencias del cambio climático, factores que influyen en la producción afectando no solo en el rendimiento y calidad de la producción sino en la rentabilidad debido al aumento de los costos de producción.

Por lo antes expuesto, el objetivo de la presente investigación es analizar el impacto económico de la gestión de costos de producción a consecuencia del cambio climático y su incidencia en la rentabilidad de la industria bananera de la provincia de El Oro.

\section{DESARROLLO:}

\section{Análisis económico a partir de los estados financieros}

El análisis económico-financiero es un proceso de recopilación, interpretación y comparación de datos cualitativos y cuantitativos, de hechos históricos y actuales de una empresa, con el propósito de obtener un diagnóstico sobre su situación real, permitiendo una adecuada toma de decisiones (Baena, 2010). Este análisis permite evaluar el desempeño de la empresa y comprobar si está cumpliendo con los objetivos.

Los informes que contienen la información económica-financiera de tipo cuantitativo expresada en términos monetarios son los estados financieros, los cuales deberán estar elaborados conforme a las Normas Internacionales de Información Financiera para dar confiabilidad en el análisis y posterior toma de decisiones, Arraiz (2018).

Este proceso se lo realiza mediante transformaciones, representaciones gráficas, ratios y otros cálculos (Bonsón, Cortijo, y Flores, 2009). El análisis de los estados financieros se basa en la utilización de herramientas y técnicas, con el propósito de obtener medidas y relaciones cuantitativas que señalen el comportamiento económico de la entidad. Las técnicas que se pueden emplear son: el análisis vertical y horizontal mediante porcentajes, y la aplicación de ratios financieros. 


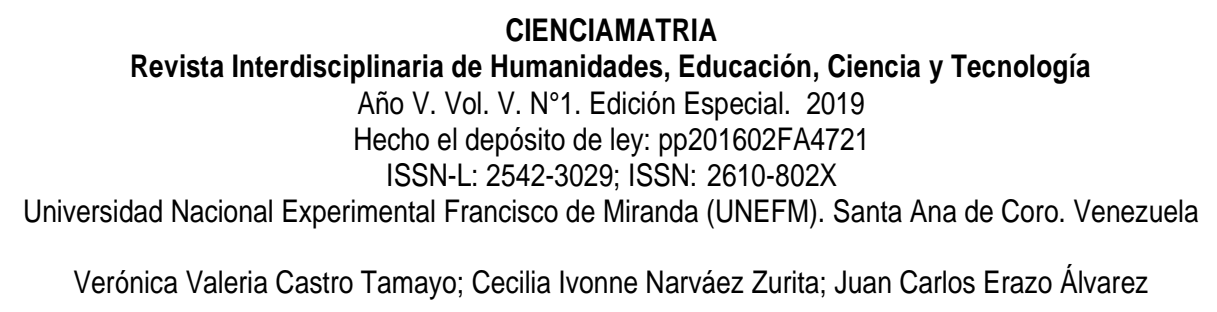

El análisis vertical consiste en tomar un estado financiero y relacionar cada una de sus cuentas con un total determinado, para estudiar la situación financiera en ese ejercicio económico sin tener en cuenta los cambios ocurridos a través del tiempo (Ortiz, 2011). La técnica del análisis horizontal analiza el crecimiento o disminución de cada cuenta o grupo de cuentas de un estado financiero de un periodo a otro, esta variación se registra en valores absolutos y valores relativos, los primeros se hallan por la diferencia de un año base y el inmediato anterior, y los segundos por la relación porcentual el año base con el de comparación., Chirinos (2016).

A la hora de evaluar el comportamiento de una empresa en términos de gestión financiera, las razones o ratios financieros son una herramienta indispensable. Las razones financieras evalúan el rendimiento de la empresa a partir del análisis de las cuentas del estado de resultados y del estado de situación financiera, no solo con la aplicación de una fórmula para calcular una razón determinada sino con su interpretación (Córdova, 2012).

Los diversos indicadores se clasifican en cuatro grupos:

(1) Razones de liquidez

(2) Razones de actividad

(3) Razones de endeudamiento

(4) Razones de rentabilidad

Las razones de liquidez evalúan la capacidad de la empresa para cumplir con sus obligaciones a corto plazo. Es decir, la capacidad de convertir sus activos corrientes en efectivo en casos de situaciones desfavorables. Las razones de liquidez son:

- Capital de trabajo neto: este no es propiamente un indicador sino más bien una forma de apreciar cuantitativa los resultados de la razón corriente.

- Razón circulante: también conocida como liquidez corriente, determina la capacidad de la empresa para cancelar sus deudas a corto plazo. Canto mayor sea la razón del circulante mayor será la capacidad de las empresas para pagar sus deudas. 


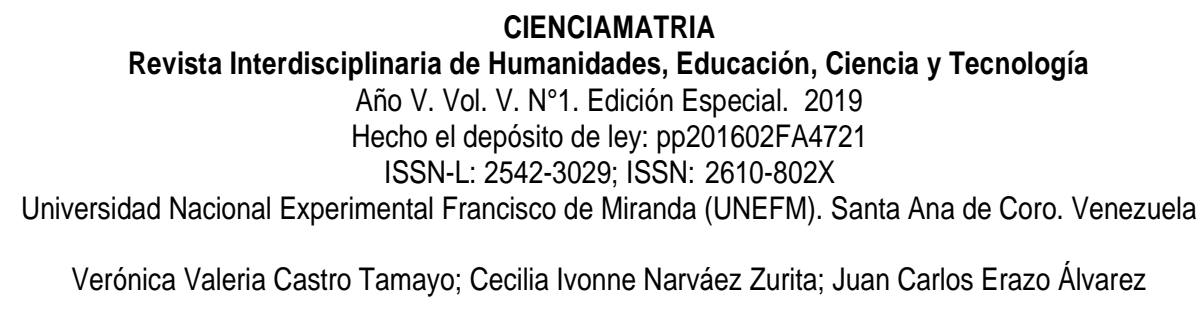

Aquellas empresas cuyo activo circulante está integrado básicamente por efectivo y cuentas por cobrar se las considera más liquidas que aquellas cuyo activo circulante consiste mayoritariamente en inventarios (Van Horne \& Wachowicz, 2002). Para ello, se utiliza una prueba más rígida que permite medir la liquidez, esta se la conoce como prueba ácida, la misma que no toma en cuenta a los inventarios en su activo circulante dado que estos pueden demorar en convertirse en efectivo.

Si se requiere conocer la eficiencia con la cual las empresas utilizan sus activos se debe aplicar los siguientes indicadores de actividad:

- Rotación de inventarios: indica el número de veces que los inventarios se convierten en efectivo o en cuentas por cobrar.

- Rotación de cartera: mide el número de veces que las cuentas por cobrar rotan o retornan en un periodo determinado.

- Período promedio de cobro: mide el tiempo promedio que se requiere para recuperar las cuentas por cobrar.

- Período promedio de pago: mide el tiempo promedio que se requiere para pagar las cuentas.

- Rotación de activos fijos: por medio de este indicador revisamos la eficiencia con la que la empresa utiliza sus activos fijos para generar ventas.

Para determinar el nivel de endeudamiento de una empresa y conocer quien ha aportado en la inversion de los activos, si los dueños o terceros ya sea a corto o largo plazo se debe aplicar los indicadores de endeudamiento, los mismos que permiten conocer la estabilidad o consolidación de una empresa en términos de la composición de los pasivos y su peso relativo con el capital y patrimonio (Córdoba, 2014).

- Endeudamiento del activo: mide la proporción del total de los activos financiados por los acreedores.

- Endeudamiento patrimonial: este índice mide cuanto está comprometido el patrimonio con los acreedores. 


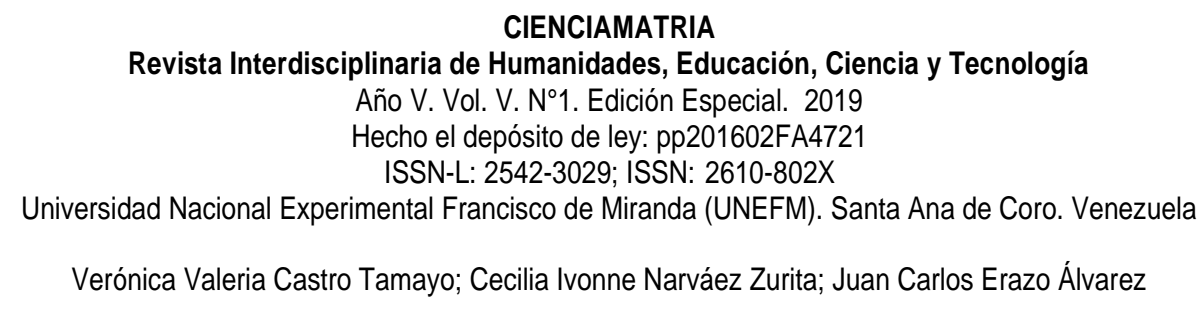

- Endeudamiento del activo fijo: el coeficiente resultante de esta relación indica la cantidad de unidades monetarias del patrimonio que la empresa posee por cada unidad monetaria invertida en activos fijos.

- Apalancamiento: determina el grado de apoyo de los recursos internos de la empresa sobre los recursos financiados por terceros.

- Apalancamiento financiero: indica la ventaja o desventaja del endeudamiento con terceros y como contribuye a la rentabilidad de la empresa.

Las razones de rentabilidad miden el rendimiento de la empresa en relación con sus ventas, activos o capital. Es importante conocer estas razones para realizar un análisis e interpretación de la utilidad, ya que una empresa necesita obtener utilidad suficiente para seguir operando (Córdoba, 2014).

- Margen de utilidad bruta: establece la relación entre la utilidad bruta en ventas y las ventas. Mide el porcentaje promedio de beneficio bruto de las ventas después de cancelar los costos de venta.

- Margen de utilidad operativa: evalúa la capacidad de la empresa para producir beneficios antes del cálculo de impuestos. No considera los gastos no operativos, como los gastos financieros (Córdoba, 2014). Mientras mayor sea este indicador mayor será la capacidad de las ventas para producir ingresos operativos sin depender de otras fuentes de ingresos.

- Margen de utilidad neta: mide la relación entre la utilidad neta e ingresos por ventas y la capacidad de generar ganancias después de impuestos. Mientras mayor sea la razón, mayor será la eficiencia de las ventas para generar beneficios.

- Rentabilidad sobre los activos (ROA): mide la capacidad de los activos de la empresa para generar utilidades. Eslava (2010) entiende por la rentabilidad económica (RE) la tasa con la que la empresa remunera a la totalidad de los recursos utilizados en su explotación, dicho en otras palabras, la RE pretende medir la capacidad del activo para generar beneficios, lo que es importante para retribuir al pasivo como a los accionistas de la empresa. La rentabilidad económica se mide 


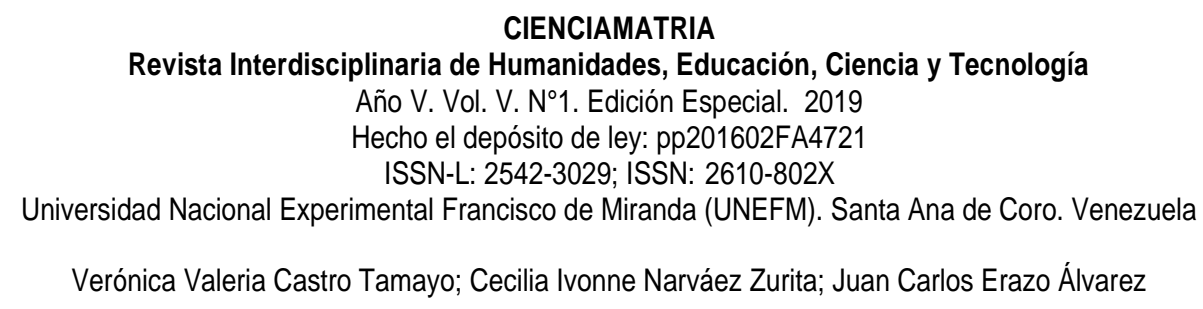

a través del ratio denominado como ROA (Return On Assets) que se presenta a continuación: $\mathrm{ROA}=$ Utilidad operacional / Activo total

Según Meigs, Williams, Haka, y Bettner (2012) esta razón se utiliza para evaluar si la gerencia ha obtenido un rendimiento razonable sobre los activos de la empresa.

- Rentabilidad sobre el patrimonio (ROE): es la razón que determina el retorno sobre la inversión de los socios o accionistas de la empresa. Dicho en otras palabras, es la razón que considera el rendimiento obtenido por parte de la gerencia sobre la inversión de los propietarios, es decir el patrimonio (Meigs et al., 2012).

El rendimiento para los accionistas es la utilidad neta, lo cual representa el rendimiento obtenido de las operaciones de la empresa, por lo tanto, el rendimiento sobre el patrimonio se calcula con la siguiente formula:

ROE $=$ Utilidad neta / Patrimonio Eslava (2010) comenta que, para muchos financieros este ratio es el más importante, por lo que un buen ratio de rentabilidad financiera es sinónimo de una empresa creciente, lo que generará un alto precio de las acciones y la aportación de nuevos recursos financieros. Para conseguir unas buenas rentabilidades y una buena gestión es imprescindible disponer de una adecuada gestión de costes de su organización.

\section{Análisis de costos de producción}

Un análisis de costos se lo debe realizar de manera histórica, presente y futura, con la intención de evaluar el pasado, controlar el presente y planear el futuro buscando de manera continua maximizar la rentabilidad del negocio (Rincón, 2009).

Laporta (2016) indica que el costo de producción es el valor de bienes y esfuerzos que afectan en los centros de producción hasta obtener un producto terminado para ser entregado al comercio.

El cálculo de costos y el análisis de costos de producción integran el sistema de información indispensable para la gestión operativa de una empresa industrial. Las empresas 


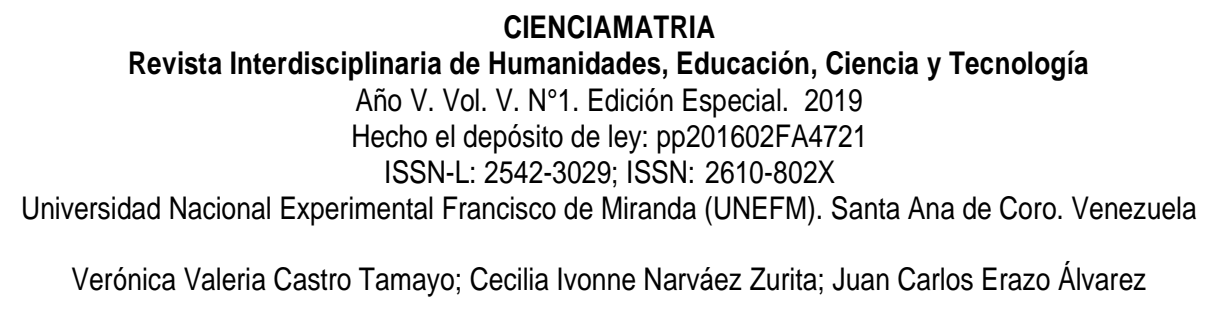

necesitan determinar cuánto les cuesta fabricar sus productos o generar servicios, establecer adecuadamente su precio de venta y conocer que productos le generan mayores rendimientos, sobre todo conocer a fondo los generadores de costos de la empresa permitirá tener un mejor control de estos y servirá de base para la toma de decisiones.

Los elementos del costo que intervienen en el proceso de producción son la materia prima, mano de obra y costos indirectos.

Materia prima: esta cuenta registra los materiales utilizados para la transformación o fabricación del producto. La materia prima se divide en materia prima directa, que son las que intervienen directamente en el proceso de producción o fabricación del producto y son de fácil asignación; y la materia prima indirecta no guardan relación directa con el producto y es compleja su asignación a cada producto.

Mano de obra: se reconoce como mano de obra al esfuerzo físico y mental de las personas que trabajan en el proceso de la elaboración de un producto. Puede ser mano de obra directa y mano de obra indirecta, la primera es el esfuerzo físico de las personas que trabajan directamente en la elaboración del producto, mientras que, la mano de obra indirecta es la que no está físicamente relacionada con la elaboración del producto.

Costos indirectos de fabricación: son aquellos costos que no se relacionan directamente con la producción o es complejo de asociarlos directamente con precisión, pero forman parte del costo de producción.

Así como se generan costos en el proceso de producción, también se generan gastos y pérdidas durante este mismo proceso, los cuales son también relevantes para la determinación de la rentabilidad de un producto (Molina, 2017). Otros costos que por su relevancia en el momento de tomar cualquier decisión merecen ser citados son los costos fijos y los costos variables. Los costos fijos son aquellos que permanecen constantes y no se ven afectados por los cambios en el volumen de producción, en contraste con los anteriores, los variables son aquellos que el costo total cambia en proporción directa con las variaciones en los volúmenes de producción (Molina, 2017). 


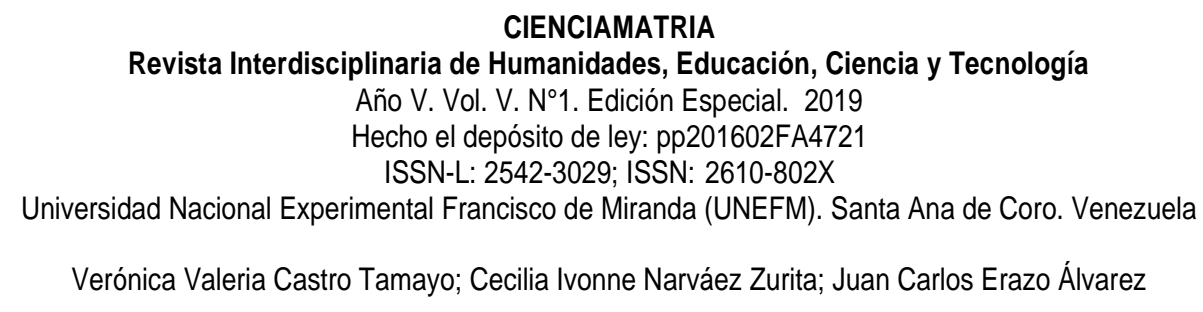

Es preciso incentivar a los usuarios internos de la información tomadores de decisiones para que reconozcan que el costo es una herramienta necesaria para confrontar realidades por la crisis ambientales, sociales, financieras que exigen planificar, controlar y tomar decisiones oportunas. El problema de las empresas es que calculan el beneficio o rentabilidad financiera tomando en cuenta los costos netamente económicos o cuantificables, cuando existen otros costos conocidos como no cuantificables que influyen también en la toma de decisiones (Molina, 2017).

Con el objeto de determinar el costo unitario del producto, se busca aplicar un conjunto de normas contables, técnicas y procedimientos de acumulación de costos. Los sistemas de costos deben atribuir el costo a los dos principales objetos de costeo: la determinación de costeo por departamento y por producto. Esta se hace en dos etapas, primero se acumulan los costos por centros de responsabilidad y luego ese costo se imputa a las unidades de producción para determinar el costo unitario (Laporta, 2016).

Hay dos clases de sistemas de costos: sistemas por órdenes de producción y sistema de costos por proceso. El sistema por órdenes de producción es un método de acumulación y distribución de costos incurridos para la fabricación de un producto de acuerdo con las especificaciones del cliente. Se inicia con el ingreso de la orden de producción, se va sumando los materiales y la mano de obra directa en cada orden, y los costos indirectos de fabricación se incrementan por departamento y posteriormente se distribuyen a las órdenes de producción.

El sistema de costos por procesos en cambio, se aplica para la producción en serie de unidades homogéneas cuya fabricación se cumple en etapas sucesivas hasta su terminación. En las empresas manufactureras o de producción que utilizan procesos continuos, el diseño de un sistema de acumulación de costos que sea apropiado, compatible y sobre todo que esté de acuerdo a las características del sector económico, es conveniente la utilización de un sistema de costos por procesos.

El sistema de costos por procesos se caracteriza por la acumulación de costos por departamento o centro de costos a diferencia del sistema de costos por órdenes donde los 


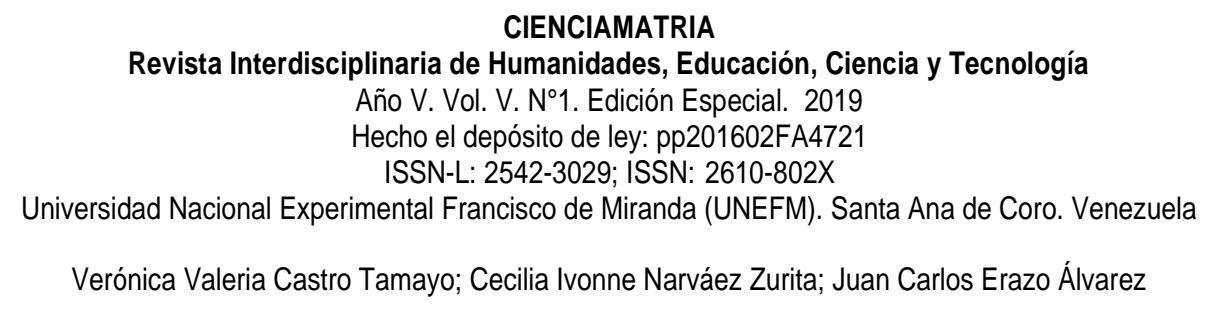

costos de materia prima, mano de obra y costos indirectos de fabricación se asignan a órdenes específicas.

Un sistema de costo determina como serán asignados los costos de manufactura incurridos durante cada periodo. El objetivo principal del costeo por proceso es determinar el costo unitario total para poder determinar el ingreso. Durante un cierto período algunos procesos iniciaran, pero no todos terminaran al final de él. En consecuencia, cada departamento determina qué parte de los costos totales incurridos en el departamento se pueden atribuir a las unidades en proceso y qué parte a las terminadas (Arredondo, 2015).

Básicamente los costos se acumulan y se registran por departamentos o proceso. El total de costos de cada proceso dividido por el total de unidades obtenidas en cada pedido da el costo unitario en cada uno de los procesos o departamentos. El costo total del producto terminado es la suma de los costos unitarios obtenidos en los diferentes procesos o departamentos (Rincón, 2009).

Por otra parte, es importante destacar que un departamento constituye una división funcional de una fábrica manufacturera en la que realizan procesos productivos, sin embargo, cabe indicar que el departamento se puede subdividir en centros de costos.

La acumulación de los costos se da en cada centro debido a que está constituido como un proceso para que al final la información no sea reportada al departamento sino en el mismo. Los departamentos o centros de costos ejercen responsabilidad sobre los costos incurridos dentro de su área de tal menara que el personal prepara un informe de costos de producción para la gerencia sobre las actividades detallando las unidades y actividades del departamento o centro de costos en un periodo de tiempo determinado.

El sistema de costos por procesos se enfoca en determinar no únicamente el costo final de cada producto, sino también el costo parcial de cada proceso de producción, con la finalidad de tener un mayor control sobre la eficiencia operacional de cada departamento. Según García (2008) y Arredondo (2015), un sistema de costeo por proceso tiene las siguientes características: 


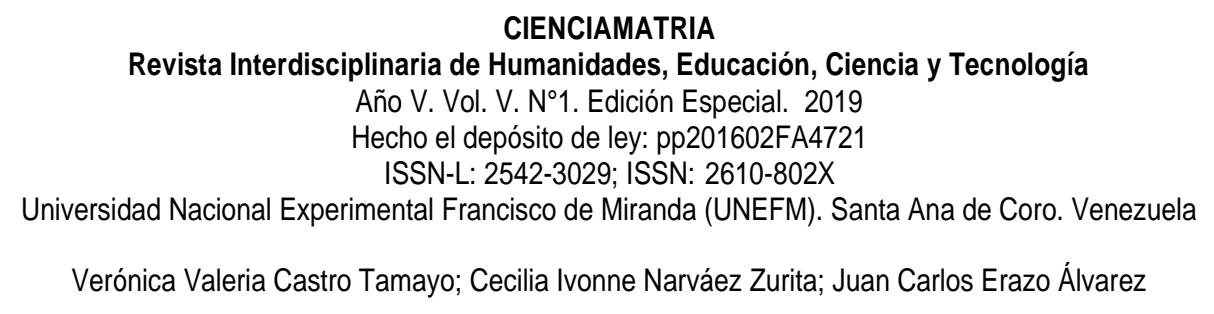

a) Los costos se acumulan por departamento o centro de costos.

b) El proceso de producción es continuo.

c) El proceso es cíclico, es decir que los procesos productivos se presentarán uno detrás de otro.

d) Cada departamento tiene su propia cuenta de inventario de trabajo en proceso en el libro mayor general. Esta cuenta se debita con los costos incurridos por el departamento, y se acredita con los costos de las unidades terminadas que van a otro departamento o a artículos terminados.

e) Las unidades equivalentes se emplean para expresar las unidades terminadas al final de un periodo.

f) Los costos totales y los costos unitarios para cada departamento se agregan, analizan y calculan de manera periódica.

El costo de ventas de una empresa industrial comprende todos los costos que se han incurrido en el proceso de producción durante un periodo, el cual se resume en el estado de costo de ventas, al punto de que el estado de resultados de una empresa industrial se apoya en el estado de costo de ventas. El estado de costos de producción y ventas se relaciona con otros estados de la siguiente manera: con el estado de resultados por el costo de ventas, que constituye la primera deducción a las ventas netas, mientras que con el estado de situación financiera se relaciona a través de los inventarios finales de materias primas, productos en proceso y productos terminados. $Y$ por su parte, estos dos estados se relacionan por la cuenta utilidad o pérdida del ejercicio (García, 2014).

\section{Costos en las empresas bananeras}

Las actividades agrícolas son muy complejas y menos controlables a diferencia de las industriales, esto debido a que es dificultoso determinar con exactitud el costo en las diferentes etapas que inicia en la preparación del terreno hasta el producto final que, para el presente estudio es el banano en cajas. Aunque la unidad final de concentración de los costos es la unidad del producto por peso, existe una unidad previa considerada como 
centro de actividad y es la hectárea cultivada, respecto de la cual se concentran los costos de producción hasta la cosecha.

\section{Influencia del cambio climático en los costos de la industria bananera.}

La Convención Marco sobre el cambio climático (CMCC), define al cambio climático como el cambio de clima atribuible directa o indirectamente a la actividad humana que altera la composición de la atmósfera mundial y que se suma a la variabilidad natural del clima observada durante periodos de tiempo comparables (CIIFEN, 2016).

El Ecuador es uno de los principales países productores y exportadores de banano. Este cultivo representa más del $22 \%$ del total de las exportaciones mundiales, el $27 \%$ del total de sus exportaciones agrícolas y el $8 \%$ del valor de todas sus exportaciones incluido el petróleo. Este sector da empleo a una parte importante de la fuerza de trabajo y más de un décimo de la población se beneficia económicamente de la producción bananera (PROECUADOR, 2016).

Según el Ministerio de Agricultura, Ganadería, Acuacultura y Pesca (MAGAP), el cultivo del banano representa el $10 \%$ de la superficie agrícola total del país y ocupa más de 165.000 hectáreas. La producción de banano en el país se concentra en las provincias de El Oro, Guayas y Los Ríos, caracterizadas por un clima húmedo tropical y suelos fértiles recomendables para el cultivo de banano.

Los efectos del cambio climático en los últimos años se han considerado como una amenaza no solo desde el punto de vista ambiental sino social económico por su impacto en los diferentes sectores sobre todo en la agricultura. Algunos de los efectos del cambio climático son: el aumento en la temperatura promedio de aire y del océano, el derretimiento de la nieve de los glaciales y los polos y la elevación del nivel del mar, que como consecuencia se obtiene cambios en los ecosistemas, en la disponibilidad de agua, en la productividad de las cosechas y en la distribución de enfermedades (Ocampo, 2011). En la siguiente tabla se muestra algunos factores climáticos y posibles efectos positivos y negativos para la agricultura. 
CIENCIAMATRIA

Revista Interdisciplinaria de Humanidades, Educación, Ciencia y Tecnología

Año V. Vol. V. N¹. Edición Especial. 2019

Hecho el depósito de ley: pp201602FA4721

ISSN-L: 2542-3029; ISSN: 2610-802X

Universidad Nacional Experimental Francisco de Miranda (UNEFM). Santa Ana de Coro. Venezuela

Verónica Valeria Castro Tamayo; Cecilia Ivonne Narváez Zurita; Juan Carlos Erazo Álvarez

\begin{tabular}{|c|c|c|c|}
\hline Factor de cambio & & Posibles beneficios & Posibles efectos negativos \\
\hline $\begin{array}{l}\text { Aumento de tem- } \\
\text { peraturas }\end{array}$ & & $\begin{array}{l}\text { Periodos de crecimiento más } \\
\text { largos } \\
\text { Periodos de crecimiento más } \\
\text { rápidos }\end{array}$ & $\begin{array}{l}\text { - } \quad \text { Aumento del estrés térmico por } \\
\text { las temperaturas } \\
\text { - } \quad \text { Aumento de hiervas malas, pla- } \\
\text { gas y enfermedades }\end{array}$ \\
\hline $\begin{array}{l}\text { Variación de la } \\
\text { precipitación }\end{array}$ & & $\begin{array}{l}\text { Aumento de la productividad } \\
\text { Disminución de la demanda de } \\
\text { agua } \\
\text { Abastecimiento de agua }\end{array}$ & $\begin{array}{l}\text { - } \quad \text { Aumento de las inundaciones y } \\
\text { salinización } \\
\text { - } \quad \text { Aumento de la frecuencia de } \\
\text { sequias } \\
\text { - } \quad \text { Aumento de hiervas malas, pla- } \\
\text { gas y enfermedades } \\
\text { - Aumento de la erosión }\end{array}$ \\
\hline $\begin{array}{l}\text { Aumento de gases } \\
\text { de efecto inverna- } \\
\text { dero }\end{array}$ & & Incremento de la fertilización & $\begin{array}{l}\text { Efectos negativos de otros ga- } \\
\text { ses }\end{array}$ \\
\hline
\end{tabular}

Fuente: Iglesias \& Medina (2009).

En el Ecuador al igual que en muchas partes del mundo surgen problemas con el clima propio de cada región, al disponer de suficiente o carencia de agua en cantidad y calidad consideradas para la producción y el proceso hacia la cosecha. Otro problema es la existencia de la mancha roja que afecta económicamente en el valor del banano. El cambio climático incrementa los síntomas de esta enfermedad, por lo que, implantar las buenas prácticas agrícolas y un correcto manejo de productos y plagas es importante. La promoción de reglas agrícolas ecológicas eficientes permitirá un sistema de producción sostenible, ecológico y equitativo para toda la red del proceso (Elbehri, y otros, 2015).

La presencia o ausencia de las lluvias, su cantidad y tiempo de permanencia es de 5 o 6 meses al año, son resultados negativos para el sector productor bananero, pues la reducción de estos niveles afecta a todos necesitando en muchos lugares incrementar sistemas de riegos tecnificados para suplir la falta de lluvias y llegar al ciclo completo de producción y exportación. El esparcimiento de las plagas y las sequias son los resultados de las altas temperaturas en la provincia de EI Oro, en Ecuador la temperatura promedio 


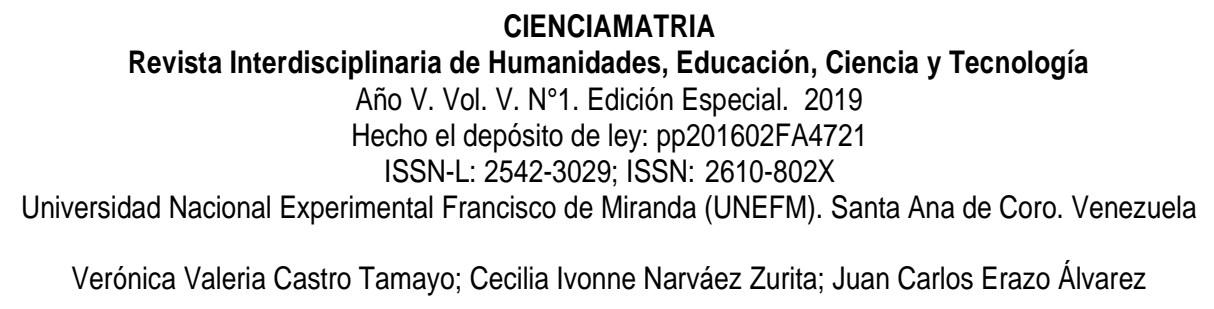

máxima anualmente es de 1.5 grados que influye en el ataque de la sigatoka a las plantaciones, llevando a los pequeños y grandes productores extender los ciclos de fumigación, lo que incrementa gastos en insumos y contaminación afectando el ambiente y la salud de la comunidad.

El conjunto de los cambios de temperaturas, intensidad de eventos meteorológicos, calidad del suelo, entre otros efectos del cambio climático, afectan a las plantaciones y a la producción bananera en su totalidad, obteniendo como consecuencia arroyamiento de las plantas, los abortos prematuros en el momento de la parición, banano con poco número de manos y dedos, de bajo calibre y fruta pequeña, menor cantidad de racimos por hectárea / semana, incluso perdida de la fruta por la caída de esta ocasionado por el insuficiente anclaje de las plantas por falta de riego, por deshidratación y por lo tanto un banano de poco peso (Elbehri, y otros, 2015).

\section{METODOLOGÍA}

La presente investigación se ejecutó bajo un diseño experimental, su enfoque fue mixto porque se recabó información y se analizó datos cuantitativos y cualitativos en el mismo estudio, los datos cualitativos fueron provenientes de la literatura revisada sobre las variables objeto de estudio y los datos cuantitativos provenientes de los resultados de un diagnóstico realizado en las unidades de análisis.

En cuanto al alcance de la investigación, fue exploratorio porque se realizó un análisis económico de la gestión de costos de producción bajo la influencia del cambio climático en la industria bananera de la provincia de El Oro. Además, se empleó el método histórico-lógico, analítico-sintético, inductivo-deductivo y estadístico. Se utilizaron las técnicas de encuestas y entrevista, para las cuales se elaboró un cuestionario de 20 preguntas dirigida a 15 empresas bananeras de la provincia. 


\section{CIENCIAMATRIA}

Revista Interdisciplinaria de Humanidades, Educación, Ciencia y Tecnología

Año V. Vol. V. NN1. Edición Especial. 2019

Hecho el depósito de ley: pp201602FA4721

ISSN-L: 2542-3029; ISSN: 2610-802X

Universidad Nacional Experimental Francisco de Miranda (UNEFM). Santa Ana de Coro. Venezuela

Verónica Valeria Castro Tamayo; Cecilia Ivonne Narváez Zurita; Juan Carlos Erazo Álvarez

\section{Tabla 2.}

Empresas encuestadas

\begin{tabular}{|l|l|}
\hline \multicolumn{1}{|c|}{$\mathbf{N}^{\circ}$} & \\
\hline 1 & PACIDEL S.A. \\
\hline 2 & LASABI S.A. \\
\hline 3 & TEFIBANANA S.A. \\
\hline 4 & BANAHYDRA S.A. \\
\hline 5 & FANOVA \\
\hline 6 & SUPREMBAN CIA LTDA \\
\hline 7 & AGRICOLA AURCRISA C.A. \\
\hline 8 & AGRICOLA BANANERA LA FLORIDA \\
\hline 9 & AGRICOLA BANANERA GREEN GOLD \\
\hline 10 & BANANAORGANIC C.A. \\
\hline 11 & COOPERATIVA DE PRODUCCION AGRICOLA BANANEROS UNIDOS COBANU \\
\hline 12 & INVERSIONES PALADINES VALVERDE \\
\hline 13 & ASOCIACION DE PRODUCCION AGRICOLA MACHALA SUR \\
\hline 14 & CSOAGRIPROVI \\
\hline
\end{tabular}

\section{RESULTADOS}

Luego de la aplicación de las técnicas de investigación, se obtuvieron los siguientes resultados:

- La mayor parte de las empresas encuestadas realizan estados financieros, y un análisis financiero para la toma de decisiones, pero no oportunamente, sino transcurrido el tiempo después que se realizó dichos estados.

- En cuanto a los costos de producción, la mayoría de empresas bananeras encuestadas tienen un sistema de costos de producción, sin embargo, no lo consideran totalmente eficiente, existen desperdicios de materiales de producción y solo el $53 \%$ llevan un control de inventario de materiales para la producción. Asimismo, 


\section{CIENCIAMATRIA}

Revista Interdisciplinaria de Humanidades, Educación, Ciencia y Tecnología

Año V. Vol. V. NN1. Edición Especial. 2019

Hecho el depósito de ley: pp201602FA4721

ISSN-L: 2542-3029; ISSN: 2610-802X

Universidad Nacional Experimental Francisco de Miranda (UNEFM). Santa Ana de Coro. Venezuela

Verónica Valeria Castro Tamayo; Cecilia Ivonne Narváez Zurita; Juan Carlos Erazo Álvarez

más del $90 \%$ consideran que los efectos del cambio climático aumentan sus costos en la producción.

- A pesar de que las empresas obtienen utilidades, la aplicación de un análisis económico de gestión de costos de producción del sector bananero ayudará a mejorar su rentabilidad.

- Con la revisión documental se puede concluir que no todas las empresas obtienen rentabilidad sobre sus activos y el patrimonio, esta rentabilidad apenas alcanza un $3 \%$, que independientemente de cómo esté financiado sus activos, éstos no están generando beneficios para las empresas, ni el patrimonio está retornando en beneficios para las mismas. Por lo tanto, un análisis profundo sobre los costos de producción será clave para ayudar a mejorar las utilidades de las empresas productoras de banano y aumentar la rentabilidad.

\section{DISCUSIÓN}

Los efectos biofísicos del cambio climático sobre la producción del banano provocan cambios en la producción y precios, que se reflejan en el sistema económico a medida que los agricultores realizan ajustes de forma autónoma en sus cultivos, uso de insumos y nivel de producción. Ante este preámbulo, se realizará un análisis a base de metodologías y herramientas para evaluar la gestión de costos de producción y su efecto en la rentabilidad. 


\section{CIENCIAMATRIA}

Revista Interdisciplinaria de Humanidades, Educación, Ciencia y Tecnología

Año V. Vol. V. №1. Edición Especial. 2019

Hecho el depósito de ley: pp201602FA4721

ISSN-L: 2542-3029; ISSN: 2610-802X

Universidad Nacional Experimental Francisco de Miranda (UNEFM). Santa Ana de Coro. Venezuela

Verónica Valeria Castro Tamayo; Cecilia Ivonne Narváez Zurita; Juan Carlos Erazo Álvarez

Figura 1.

Esquema de la propuesta de análisis

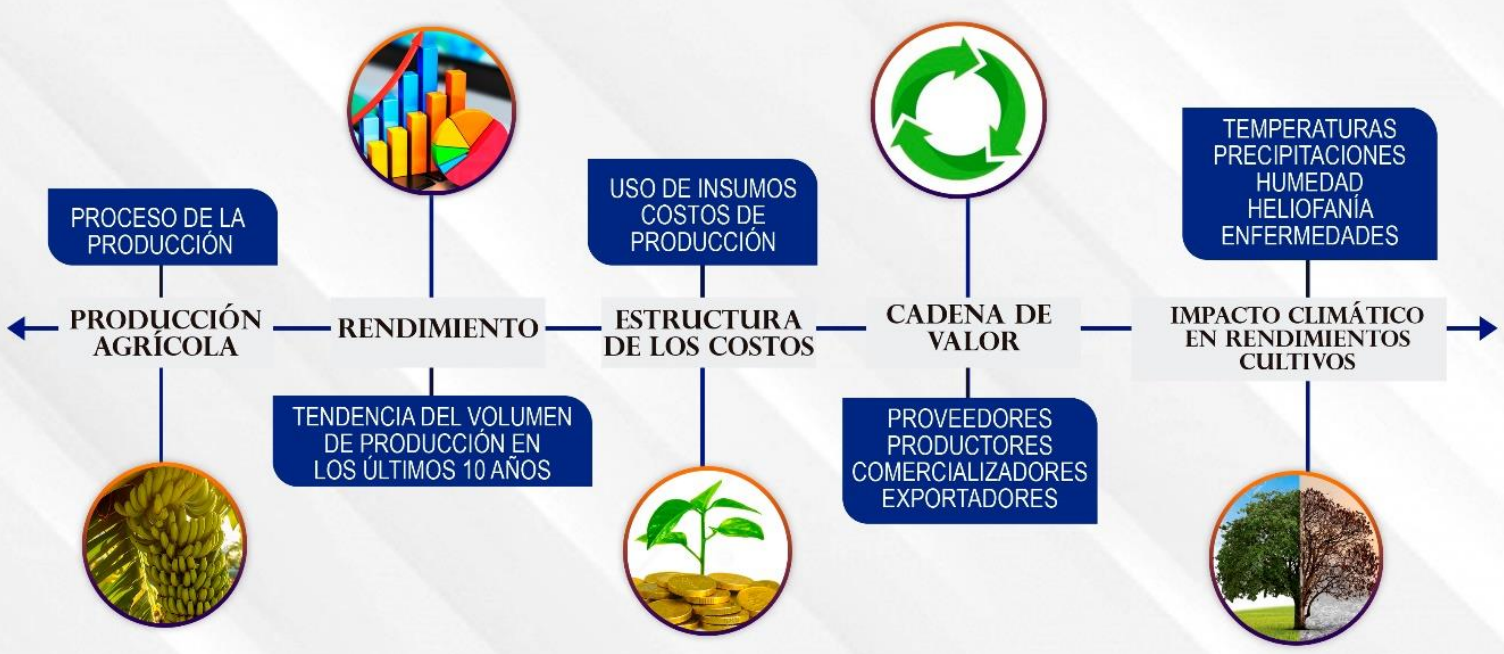

En la siguiente figura se presenta las diferentes actividades que se desarrollan en las 3 etapas del proceso de producción hasta obtener el producto en caja.

Figura 2.

Proceso de producción 


\section{CIENCIAMATRIA}

Revista Interdisciplinaria de Humanidades, Educación, Ciencia y Tecnología

Año V. Vol. V. NN1. Edición Especial. 2019

Hecho el depósito de ley: pp201602FA4721

ISSN-L: 2542-3029; ISSN: 2610-802X

Universidad Nacional Experimental Francisco de Miranda (UNEFM). Santa Ana de Coro. Venezuela

Verónica Valeria Castro Tamayo; Cecilia Ivonne Narváez Zurita; Juan Carlos Erazo Álvarez

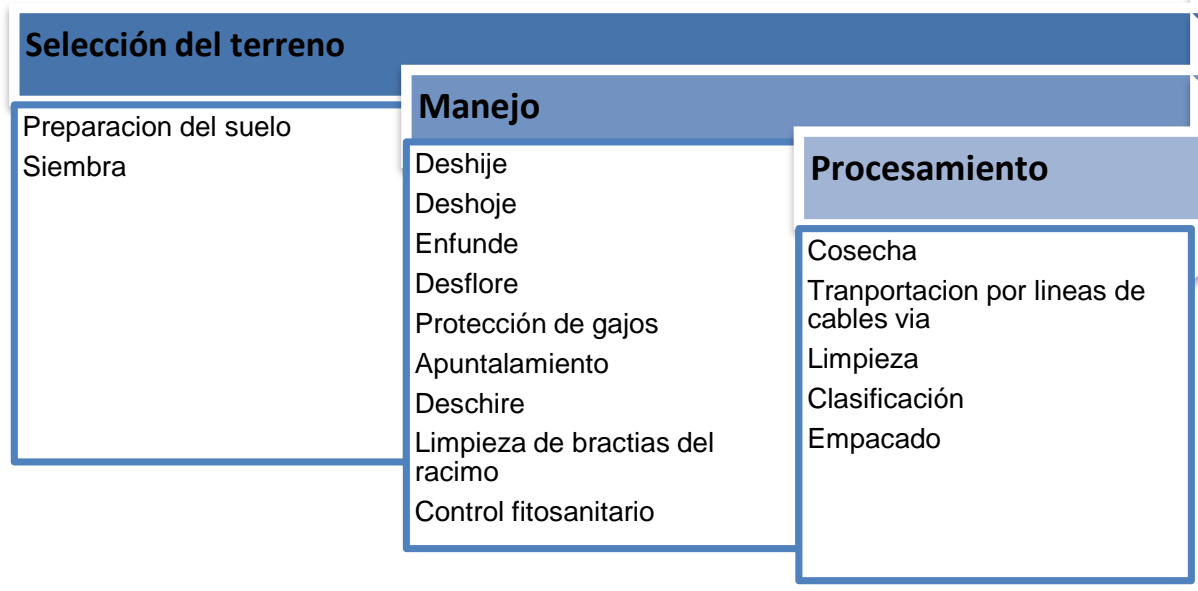

\section{a) Volumen de producción de banano}

En el siguiente cuadro se muestra la producción de banano en la provincia de El Oro en los últimos 10 años.

\section{Tabla 3}

Producción de banano en la provincia El Oro

\section{Producción de banano - Producción de El Oro}

\begin{tabular}{|cccc|}
\hline Años & $\begin{array}{c}\text { Superficie Plantada } \\
\text { (ha) }\end{array}$ & Cosecha (ha) & $\begin{array}{c}\text { Producción (tonela- } \\
\text { das) }\end{array}$ \\
\hline $\mathbf{2 0 0 9}$ & $56,886.58$ & $54,557.70$ & $1,861,662.00$ \\
\hline $\mathbf{2 0 1 0}$ & $57,657.39$ & $54,686.53$ & $1,892,647.37$ \\
\hline $\mathbf{2 0 1 1}$ & 55.163 .26 & $54,625.10$ & $2,443,672.99$ \\
\hline $\mathbf{2 0 1 2}$ & $63,883.02$ & $62,828.27$ & $2,269,901.37$ \\
\hline $\mathbf{2 0 1 3}$ & $64,093.50$ & $62,666.98$ & $2,594,000.41$ \\
\hline $\mathbf{2 0 1 4}$ & $33,711.31$ & $32,467.94$ & $1,020,380.68$ \\
\hline $\mathbf{2 0 1 5}$ & $39,953.28$ & $39,117.75$ & $1,387,003.36$ \\
\hline $\mathbf{2 0 1 6}$ & $42,513.26$ & $42,340.40$ & $1,075,395.11$ \\
\hline $\mathbf{2 0 1 7}$ & $46,055.61$ & $42,291.99$ & $1,484,078.16$ \\
\hline $\mathbf{2 0 1 8}$ & $43,066.00$ & $39,403.00$ & $1,562,203.00$ \\
\hline
\end{tabular}

Fuente: Tabulados de ESPAC - INEC 


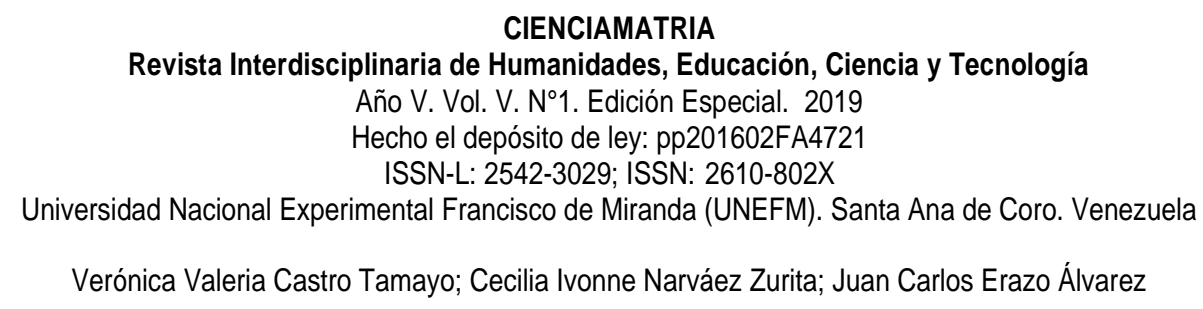

\section{b) Factores climáticos}

Según la guía de buenas prácticas agrícolas para el banano emitidas por el Ministerio de Agricultura, Ganadería, Acuacultura y Pesca (2014), a continuación, se explican los factores climáticos que se deben considerar para el manejo de los cultivos:

\begin{tabular}{|c|c|c|}
\hline Factor climático & Conveniente & No conveniente \\
\hline Temperatura & De $20^{\circ} \mathrm{C}$ a $35,5^{\circ} \mathrm{C}$ & Menor a $20^{\circ}$ \\
\hline Precipitación & $\begin{array}{l}\text { Pluviosidad de } 120 \text { a } 180 \mathrm{~mm} \text { de } \\
\text { lluvia mensual o Precipitaciones } \\
\text { media semanales de } 28 \text { a } 42 \mathrm{~mm}\end{array}$ & \\
\hline Luminosidad & $\begin{array}{l}\text { Alta luminosidad, promedio de } 4 \\
\text { horas de brillo solar por día }\end{array}$ & \\
\hline Viento & $\begin{array}{l}\text { Ausencia de vientos o que no su- } \\
\text { peren los } 30 \mathrm{~km} \text { por hora }\end{array}$ & $\begin{array}{l}\text { Vientos que superen los } 30 \mathrm{~km} \\
\text { por hora porque provocan volca- } \\
\text { miento de plantas. }\end{array}$ \\
\hline Humedad relativa & Menor a $80 \%$ & $\begin{array}{l}\text { Mayor a } 80 \% \text { produce el desarro- } \\
\text { llo de enfermedades. }\end{array}$ \\
\hline Altitud & $\begin{array}{l}\text { Altura de } 0 \text { a } 300 \text { metros sobre el } \\
\text { nivel del mar (msnm) }\end{array}$ & $\begin{array}{l}\text { Suelos a nivel del mar, inunda- } \\
\text { bles o que no tienen capacidad } \\
\text { de evacuación del agua. }\end{array}$ \\
\hline
\end{tabular}

Fuente: (Ministerio de Agricultura, Ganadería, Acuacultura y Pesca, 2014)

Se realizó el respectivo análisis de los datos de la estación del Instituto Nacional de Meteorología e Hidrología y hay dos factores climáticos que impactan directamente en la producción los cuales son temperatura y precipitación. La temperatura en la Prov. De El Oro oscila entre $20^{\circ} \mathrm{C}$ a $35,5^{\circ} \mathrm{C}$ promedio, lo cual es lo conveniente para la producción bananera. La precipitación influye mucho en la producción del banano, aumentando el 


\section{CIENCIAMATRIA}

Revista Interdisciplinaria de Humanidades, Educación, Ciencia y Tecnología

Año V. Vol. V. N¹. Edición Especial. 2019

Hecho el depósito de ley: pp201602FA4721

ISSN-L: 2542-3029; ISSN: 2610-802X

Universidad Nacional Experimental Francisco de Miranda (UNEFM). Santa Ana de Coro. Venezuela

Verónica Valeria Castro Tamayo; Cecilia Ivonne Narváez Zurita; Juan Carlos Erazo Álvarez

peso de la fruta; teniendo en cuenta la estación meteorológica de Machala la temporada de mayor precipitación empieza en diciembre siendo sus picos febrero y marzo y terminando en junio; de igual manera los meses más fríos son los de julio hasta noviembre, empezando a incrementarse desde diciembre, esto beneficia al cultivo existiendo relación de estos eventos con los meses de mayor producción. Otro factor climático de importancia es la humedad relativa, esta no tiene impacto en la producción de banano pero si tiene impacto en el ciclo de vida de los hongos, si existe una humedad relativa alta existe mayor cantidad de infecciones fungosas por lo que se deberá gastar en más ciclos de fumigación, lo que impacta en los costos de producción. 


\section{CIENCIAMATRIA}

Revista Interdisciplinaria de Humanidades, Educación, Ciencia y Tecnología

Año V. Vol. V. N¹. Edición Especial. 2019

Hecho el depósito de ley: pp201602FA4721

ISSN-L: 2542-3029; ISSN: 2610-802X

Universidad Nacional Experimental Francisco de Miranda (UNEFM). Santa Ana de Coro. Venezuela

Verónica Valeria Castro Tamayo; Cecilia Ivonne Narváez Zurita; Juan Carlos Erazo Álvarez

\section{c) Costos de producción}

Tabla 5.

Costos de producción

Hacienda 200 Has Aprox.

\begin{tabular}{|l|l|l|l|c|c|c|c|c|c|}
\hline 2009 & 2010 & 2011 & 2012 & 2013 & 2014 & 2015 & 2016 & 2017 & 2018 \\
\hline
\end{tabular}

Productividad / Cajas Por Hectárea

OSTO POR HECTAREA

Actividades De Producción

\begin{tabular}{|c|c|c|c|c|c|c|c|c|c|c|}
\hline Control de población & $\$ 164$ & $\$ 186$ & $\$ 208$ & $\$ 231$ & $\$ 253$ & $\$ 275$ & $\$ 297$ & $\$ 320$ & $\$ 342$ & $\$ 485$ \\
\hline Control de Malezas & $\$ 265$ & $\$ 265$ & $\$ 264$ & $\$ 264$ & $\$ 263$ & $\$ 263$ & $\$ 262$ & $\$ 262$ & $\$ 261$ & $\$ 241$ \\
\hline Fertilización & $\$ 2,040$ & $\$ 2,042$ & $\$ 2,043$ & $\$ 2,044$ & $\$ 2,045$ & $\$ 2,046$ & $\$ 2,048$ & $\$ 2,049$ & $\$ 2,050$ & $\$ 2,238$ \\
\hline Loteros Aéreos & $\$ 2,265$ & $\$ 2,265$ & $\$ 2,265$ & $\$ 2,265$ & $\$ 2,266$ & $\$ 2,266$ & $\$ 2,266$ & $\$ 2,267$ & $\$ 2,267$ & $\$ 2,326$ \\
\hline Limpieza de Matas & $\$ 230$ & $\$ 230$ & $\$ 230$ & $\$ 231$ & $\$ 231$ & $\$ 231$ & $\$ 231$ & $\$ 232$ & $\$ 232$ & $\$ 237$ \\
\hline Deshoje & $\$ 416$ & $\$ 416$ & $\$ 415$ & $\$ 414$ & $\$ 413$ & $\$ 413$ & $\$ 412$ & $\$ 411$ & $\$ 411$ & $\$ 362$ \\
\hline Control de Plagas & $\$ 21$ & $\$ 37$ & $\$ 53$ & $\$ 69$ & $\$ 85$ & $\$ 101$ & $\$ 117$ & $\$ 133$ & $\$ 149$ & $\$ 205$ \\
\hline Riego \& Drenaje & $\$ 1,179$ & $\$ 1,180$ & $\$ 1,181$ & $\$ 1,182$ & $\$ 1,183$ & $\$ 1,185$ & $\$ 1,186$ & $\$ 1,187$ & $\$ 1,188$ & $\$ 1,298$ \\
\hline Control Sigatoka & $\$ 1,048$ & $\$ 1,048$ & $\$ 1,047$ & $\$ 1,046$ & $\$ 1,046$ & $\$ 1,045$ & $\$ 1,044$ & $\$ 1,044$ & $\$ 1,043$ & $\$ 935$ \\
\hline Administración Hcda. & $\$ 1,095$ & $\$ 1,099$ & $\$ 1,102$ & $\$ 1,106$ & $\$ 1,109$ & $\$ 1,113$ & $\$ 1,117$ & $\$ 1,120$ & $\$ 1,124$ & $\$ 1,332$ \\
\hline Cosecha Fijo & $\$ 87$ & $\$ 89$ & $\$ 90$ & $\$ 92$ & $\$ 93$ & $\$ 95$ & $\$ 96$ & $\$ 98$ & $\$ 99$ & $\$ 110$ \\
\hline Empaque Fijo & $\$ 70$ & $\$ 71$ & $\$ 71$ & $\$ 72$ & $\$ 73$ & $\$ 73$ & $\$ 74$ & $\$ 75$ & $\$ 75$ & $\$ 79$ \\
\hline Total Costo Fijo & $\$ 8,881$ & $\$ 8,926$ & $\$ 8,971$ & $\$ 9,016$ & $\$ 9,061$ & $\$ 9,106$ & $\$ 9,152$ & $\$ 9,197$ & $\$ 9,242$ & $\$ 9,849$ \\
\hline Cosecha & $\$ 1,219$ & $\$ 1,219$ & $\$ 1,219$ & $\$ 1,219$ & $\$ 1,219$ & $\$ 1,219$ & $\$ 1,219$ & $\$ 1,219$ & $\$ 1,219$ & $\$ 1,226$ \\
\hline Empaque & $\$ 1,839$ & $\$ 1,839$ & $\$ 1,839$ & $\$ 1,840$ & $\$ 1,840$ & $\$ 1,840$ & $\$ 1,841$ & $\$ 1,841$ & $\$ 1,842$ & $\$ 1,908$ \\
\hline Transporte & $\$ 1,076$ & $\$ 1,076$ & $\$ 1,076$ & $\$ 1,076$ & $\$ 1,076$ & $\$ 1,076$ & $\$ 1,076$ & $\$ 1,076$ & $\$ 1,076$ & $\$ 1,065$ \\
\hline Total & $\$ 4,133$ & $\$ 4,134$ & $\$ 4,134$ & $\$ 4,134$ & $\$ 4,135$ & $\$ 4,135$ & $\$ 4,136$ & $\$ 4,136$ & $\$ 4,136$ & $\$ 4,198$ \\
\hline
\end{tabular}




\section{CIENCIAMATRIA}

Revista Interdisciplinaria de Humanidades, Educación, Ciencia y Tecnología

Año V. Vol. V. No1. Edición Especial. 2019

Hecho el depósito de ley: pp201602FA4721

ISSN-L: 2542-3029; ISSN: 2610-802X

Universidad Nacional Experimental Francisco de Miranda (UNEFM). Santa Ana de Coro. Venezuela

Verónica Valeria Castro Tamayo; Cecilia Ivonne Narváez Zurita; Juan Carlos Erazo Álvarez

\begin{tabular}{|c|c|c|c|c|c|c|c|c|c|c|}
\hline Costo Total Operativo & $\$ 13,014$ & $\$ 13,059$ & $\$ 13,105$ & $\$ 13,150$ & $\$ 13,196$ & 13,242 & 13,287 & 13,333 & 13,378 & $\$ 14,047$ \\
\hline Costo Por Caja & $\$ 4.63$ & $\$ 4.64$ & $\$ 4.66$ & $\$ 4.68$ & $\$ 4.69$ & $\$ 4.71$ & $\$ 4.72$ & $\$ 4.74$ & $\$ 4.76$ & $\$ 4.97$ \\
\hline Precio De Venta & $\$ 5.05$ & $\$ 5.40$ & $\$ 5.69$ & $\$ 6.25$ & $\$ 6.22$ & $\$ 5.00$ & $\$ 6.55$ & $\$ 6.16$ & $\$ 6.26$ & $\$ 6.20$ \\
\hline Utilidad Operativa & $\$ 0.42$ & $\$ 0.76$ & $\$ 1.03$ & $\$ 1.57$ & $\$ 1.53$ & $\$ 0.29$ & $\$ 1.83$ & $\$ 1.42$ & $\$ 1.50$ & $\$ 1.23$ \\
\hline
\end{tabular}




\section{CIENCIAMATRIA}

Revista Interdisciplinaria de Humanidades, Educación, Ciencia y Tecnología

Año V. Vol. V. №1. Edición Especial. 2019

Hecho el depósito de ley: pp201602FA4721

ISSN-L: 2542-3029; ISSN: 2610-802X

Universidad Nacional Experimental Francisco de Miranda (UNEFM). Santa Ana de Coro. Venezuela

Verónica Valeria Castro Tamayo; Cecilia Ivonne Narváez Zurita; Juan Carlos Erazo Álvarez

\section{Análisis vertical}

HACIENDA 200 HAS APROX.

Costo Por Hectárea

\begin{tabular}{|c|c|c|c|c|}
\hline Productividad / Cajas Por Hectárea & 2,812 & & 2,827 & \\
\hline Actividades De Producción & 2009 & Variación & 2018 & Variación \\
\hline VENTAS & $14,201.90$ & $100 \%$ & $17,529.18$ & $100 \%$ \\
\hline Control de Población & 163.71 & $1.15 \%$ & 485.03 & $2.77 \%$ \\
\hline Control de Malezas & 265.46 & $1.87 \%$ & 241.27 & $1.38 \%$ \\
\hline Fertilización & $2,040.47$ & $14.37 \%$ & $2,238.39$ & $12.77 \%$ \\
\hline Loteros Aéreos & $2,264.69$ & $15.95 \%$ & $2,326.33$ & $13.27 \%$ \\
\hline Limpieza de Matas & 230.02 & $1.62 \%$ & 237.47 & $1.35 \%$ \\
\hline Deshoje & 416.21 & $2.93 \%$ & 362.10 & $2.07 \%$ \\
\hline Control de Plagas & 20.69 & $0.15 \%$ & 204.86 & $1.17 \%$ \\
\hline Riego \& Drenaje & $1,178.64$ & $8.30 \%$ & $1,297.92$ & $7.40 \%$ \\
\hline Control Sigatoka & $1,048.21$ & $7.38 \%$ & 935.32 & $5.34 \%$ \\
\hline Administración Hcda. & $1,094.92$ & $7.71 \%$ & $1,331.60$ & $7.60 \%$ \\
\hline Cosecha Fijo & 87.38 & $0.62 \%$ & 109.54 & $0.62 \%$ \\
\hline Empaque Fijo & 70.14 & $0.49 \%$ & 79.34 & $0.45 \%$ \\
\hline Total Costo Fijo & $8,880.56$ & $62.53 \%$ & $9,849.17$ & $56.19 \%$ \\
\hline Cosecha & $1,218.96$ & $8.58 \%$ & $1,225.72$ & $6.99 \%$ \\
\hline Empaque & $1,838.52$ & $12.95 \%$ & $1,907.91$ & $10.88 \%$ \\
\hline Transporte & $1,075.86$ & $7.58 \%$ & $1,064.64$ & $6.07 \%$ \\
\hline Total Costo Variable & $4,133.34$ & $29.10 \%$ & $4,198.27$ & $23.95 \%$ \\
\hline Costo Total Operativo Por Hectárea & $13,013.90$ & $91.63 \%$ & $14,047.44$ & $80.14 \%$ \\
\hline Utilidad Bruta & $1,188.00$ & $8.37 \%$ & $3,481.75$ & $19.86 \%$ \\
\hline
\end{tabular}

Para temas de análisis se consideró la información de una hacienda productora de banano de la provincia de El Oro de aproximadamente 200 hectáreas, la cual emplea el 


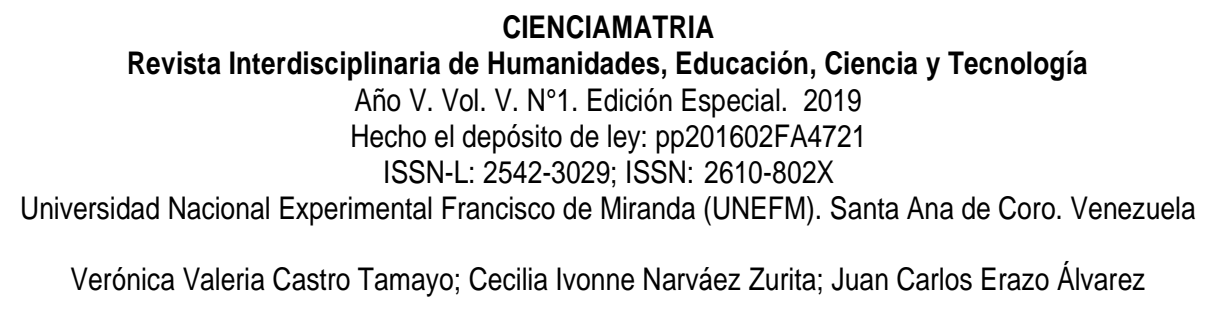

sistema de costos por procesos. Se realiza un análisis vertical del estado de resultados del año 2009 tomando como 100\% el reglón de las ventas totales por hectárea, y se determina lo siguiente:

Del total de las ventas por hectárea en el año 2009, el 91.63\% representa al costo total de producción por hectárea y el $8.37 \%$ a la utilidad bruta.

La mayor parte de los costos de producción se concentra en Loteros aéreos con el $15.95 \%$, esta operación se la realiza con una funda de polietileno perforada de dimensiones convenientes, para proteger a la fruta de los insectos y el roce de las hojas, obteniendo así una fruta limpia, de mejor presentación y calidad, la misma que permanece hasta la cosecha.

El $14.37 \%$ corresponde al costo por fertilización, esto debido a que esta es una de las actividades de mayor importancia que consiste en incorporar abonos al sueldo para obtener buenos rendimientos en la producción y se lo realiza para todo el ciclo en función de las condiciones climáticas, cabe mencionar que la fertilidad del suelo disminuye rápidamente después de los primeros años, por lo tanto, estos costos son representativos al ser una hacienda con mucho tiempo en el proceso de producción de banano.

Del total de las ventas, el $12.95 \%$ corresponde al costo por empaque clasificado como un costo variable, incluye rubros como la mano de obra y ciertos costos indirectos necesarios para la labor de sellado de la fruta y la armada y pegada de la caja.

La actividad por Control Sigatoka representa el 7.38\%, la Sigatoka es una enfermedad causada por el hongo Mycosphaerella fijiensis, y el único control es el químico fungicidas de contacto y sistémicos.

Del total de ventas apenas el $0.15 \%$ corresponde a control de plagas, esta actividad se refiere al manejo integrado de plagas y enfermedades que realiza el productor aplicando medidas biológicas, biotécnicas, químicas, de cultivo o de selección de vegetales racionalmente con la finalidad que la utilización de productos fitosanitarios químicos sea el 
mínimo necesario para mantener la población de plaga en niveles inferiores evitando daños o perdidas económicas. En el año 2009 por las condiciones climáticas fueron óptimas para la producción por lo que, casi no fue necesario generar costos por control de plagas. Para analizar el comportamiento de los costos luego de aproximadamente nueve años, se realiza un análisis vertical al estado de resultados del año 2018, y se observa lo siguiente:

Del total de las ventas por hectárea, el $80.14 \%$ representa al total de costo de producción por hectárea y el $19.86 \%$ a la utilidad bruta, siendo los mayores porcentajes de costos los correspondientes a costos por Loteros aéreos con el 13.27\% y costos por fertilización con el $12.77 \%$. Se considera un costo medio al costo por transporte clasificado como un costo variable ya que varía de acuerdo al número de cajas que se va a transportar, en el año 2018 este costo corresponde el $6.07 \%$ del total de las ventas.

\section{Análisis horizontal}

HACIENDA 200 HAS APROX.

PRODUCTIVIDAD / CAJAS POR HECTAREA $\quad 2,812 \quad 2,827$

\begin{tabular}{|l|l|l|l|l|}
\hline ACTIVIDADES DE PRODUCCION & 2009 & 2018 & ABSOLUTA & RELATIVA \\
\hline
\end{tabular}

\begin{tabular}{lrrrr} 
VENTAS & $\$ 14,201.90$ & $\$ 17,529.18$ & $\$ 3,327.28$ & $23 \%$ \\
\hline Control De Población & 163.71 & 485.03 & 321.32 & $196 \%$ \\
Control De Malezas & 265.46 & 241.27 & -24.19 & $-9 \%$ \\
Fertilización & $2,040.47$ & $2,238.39$ & 197.92 & $10 \%$ \\
Loteros Aéreos & $2,264.69$ & $2,326.33$ & 61.64 & $3 \%$ \\
Limpieza De Matas & 230.02 & 237.47 & 7.45 & $3 \%$ \\
Deshoje & 416.21 & 362.10 & -54.12 & $-13 \%$ \\
Control De Plagas & 20.69 & 204.86 & 184.17 & $890 \%$ \\
Riego \& Drenaje & $1,178.64$ & $1,297.92$ & 119.28 & $10 \%$ \\
Control Sigatoka & $1,048.21$ & 935.32 & -112.89 & $-11 \%$ \\
Administración Hcda. & $1,094.92$ & $1,331.60$ & 236.68 & $22 \%$ \\
Cosecha Fijo & 87.38 & 109.54 & 22.16 & $25 \%$
\end{tabular}


Verónica Valeria Castro Tamayo; Cecilia Ivonne Narváez Zurita; Juan Carlos Erazo Álvarez

\begin{tabular}{lrrrr} 
Empaque Fijo & \multicolumn{1}{c}{70.14} & 79.34 & 9.19 & $13 \%$ \\
Total Costo Fijo & $\$ 8,881$ & $\$ 9,849$ & $\$ 969$ & $11 \%$ \\
Cosecha & $\$ 1,219$ & $\$ 1,226$ & 6.75 & $1 \%$ \\
Empaque & $\$ 1,839$ & $\$ 1,908$ & 69.39 & $4 \%$ \\
Transporte & $\$ 1,076$ & $\$ 1,065$ & -11.21 & $-1 \%$ \\
Total Costo Variable & $\$ 4,133$ & $\$ 4,198$ & $\$ 65$ & $2 \%$ \\
Costo Total Operativo Por Hectárea & $\$ 13,014$ & $\$ 14,047$ & $\$ 1,034$ & $8 \%$ \\
Utilidad Bruta & $\$ 1,188.00$ & $\$ 3,481.75$ & $\$ 2,293.74$ & $193 \%$
\end{tabular}

Para analizar el crecimiento o disminución de cada cuenta o grupo de cuentas de un periodo a otro se aplicó el análisis horizontal al estado de resultados. Como base se toma el año 2009 con el fin de conocer el comportamiento de los costos de producción al año 2018, obteniendo los siguientes resultados:

En el año 2018 las ventas crecieron un 23\% con respecto al año 2009, esto debido al alza en el precio oficial de la caja de banano, en el año 2009 la caja se vendió a \$5.05 y en el año 2018 su precio tuvo un incremento de $\$ 1.23$.

El costo por control de población tuvo un incremento del 196\% con respecto al año 2009, esta actividad consiste en la eliminación de retoños o hijos que no son productivos, nacidos al pie de cada planta. Se utiliza para seleccionar el hijo adecuado de la planta que permitirá una producción uniforme durante el año, asegurando un buen rendimiento y calidad. También se lo conoce como: deshije, selección o trasplante, y es la actividad de mayor concentración de costos.

El costo por control de maleza al año 2018 disminuyó un 9\% con respecto al año base, esta actividad se lo realiza mediante "rozas o chapias" con machete.

El costo por Fertilización incrementó un $10 \%$ ya que esta actividad se la realiza mensualmente a toda la plantación durante todo el ciclo vegetativo de la planta.

La actividad de loteros aéreos en el año 2018 tiene un incremento del 3\% con respecto al año 2009, a igual proporción incrementa el costo por limpieza de matas.

El costo por Deshoje, tiene una disminución de 13\% al año 2018, esta actividad consiste en eliminar las hojas secas, viejas y quebradas que pueda causar la prolongación de 


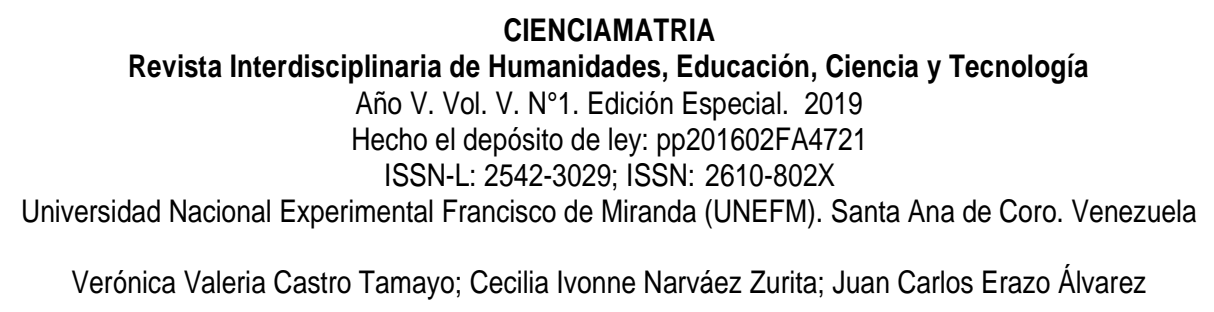

enfermedad o afectar a la calidad del racimo, esta disminución es provecho de la ausencia de vientos y altas temperaturas.

El costo por control de plagas incrementa 890\% en el año 2018 en comparación al costo de hace nueve años atrás, este aumento responde a que cada año el uso de productos químicos para el control de plagas es mayor y necesario para evitar la propagación de enfermedades en las plantas y comprometer su rendimiento o existencia, aunque el uso de estos químicos traiga grandes consecuencias negativas para el medio ambiente. Un aumento de la temperatura estaría relacionado a un aumento de la humedad relativa por lo que, provocó mayores ciclos de fumigación dado que una humedad relativa alta es ideal para el desarrollo de enfermedades fungosas.

Los costos por riego y drenaje tuvieron un incremento del $10 \%$ con respecto al 2009, esta actividad consiste en aplicar artificialmente agua al cultivo permitiendo satisfacer las necesidades de humedad del suelo para alcanzar niveles óptimos de productividad, el aumento en costos por riego no es mayor por la conveniente humedad que hubo en el periodo en análisis.

Los costos por control de la Sigatoka en el año 2018 disminuyeron el 11\% con respecto al año 2009. Los costos incurridos por Administración de la hacienda representan un incremento de $22 \%$ con respecto a los de hace nueve años atrás. Estos costos son inherentes a la gestión del Banano como son los sueldos, materiales de los administradores y jefes de campo, también incluye certificaciones. Los costos de la actividad denominada cosecha fijo aumentó el $22 \%$ con respecto al año base y los costos por empaque fijo incrementó el 13\%.

Dentro de los costos variables, el costo por actividad de cosecha tuvo un incremento del $1 \%$, esta actividad consiste en sacar del campo la fruta, cuando ha completado su madurez fisiológica, el incremento no es considerable. El costo por empaque incrementó el 4\% lo que sería ocasionado por un aumento de cajas, y el costo por transporte disminuyó el 1\% con relación al año 2009.

Es claro que el incremento de costos en la producción de banano mayormente se da por 


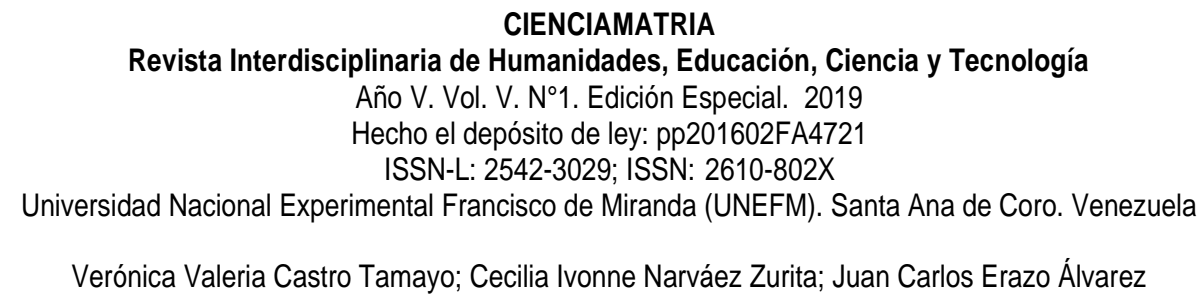

fertilización de suelos y en control de plagas. El control de plagas se ha convertido en una odisea para los productores, por los costos que se incurren en químicos como fungicidas e insecticidas para evitar las enfermedades a las plantaciones, que aumentan o disminuyen de acuerdo a las condiciones climáticas.

Finalmente se analiza el margen de utilidad bruta, aplicando la ratio de rentabilidad, que arroja el mismo resultado aplicando el análisis vertical.

Formula

2009

2018

Utilidad bruta $/$ Ventas $\quad 1,188.00 / 14,201.90=8.37 \% \quad 3,481.75 / 17,529.18=19.86 \%$

Para el año 2009 la utilidad bruta representa el 8.37\% con respecto a las ventas. En el 2018 la utilidad bruta representa el $19.86 \%$ del total de las ventas. Si analizamos horizontalmente la utilidad bruta al 2018 incrementa en un 193\% con respecto al año base 2009 . Si bien el costo total de producción por hectárea incrementa en un 8\% y la utilidad bruta incrementa el $193 \%$ esto gracias al aumento del precio oficial de la caja de banano, pues si esta se mantuviera a través del tiempo el productor caería en pérdidas en su ejercicio.

\section{REFERENCIAS CONSULTADAS}

1. Arredondo González, M. (2015). Contabilidad y Análisis de Costos (2ª edición ed.). México: Grupo Editorial Patria.

2. Arraiz, A. (2018). Framerwork de desarrollo de Proyectos Sociotecnológicos basado en la notación de Metamodelos de procesos de Ingeniería de Software (spem 2.0). Revista Arbitrada Interdisciplinaria Koinonía, 3(6), 79-95. Recuperado de https://fundacionkoinonia.com.ve/ojs/index.php/revistakoinonia/article/view/141/121

3. Baena, D. (2010). Análisis financiero. Bogotá: Ecoe Ediciones.

4. Bonsón, E., Cortijo, V., \& Flores, F. (2009). Análisis de estados financieros. Madrid: Pearson.

5. CIIFEN. (2016). Centro Internacional para la Investigación del Fenómeno de El 


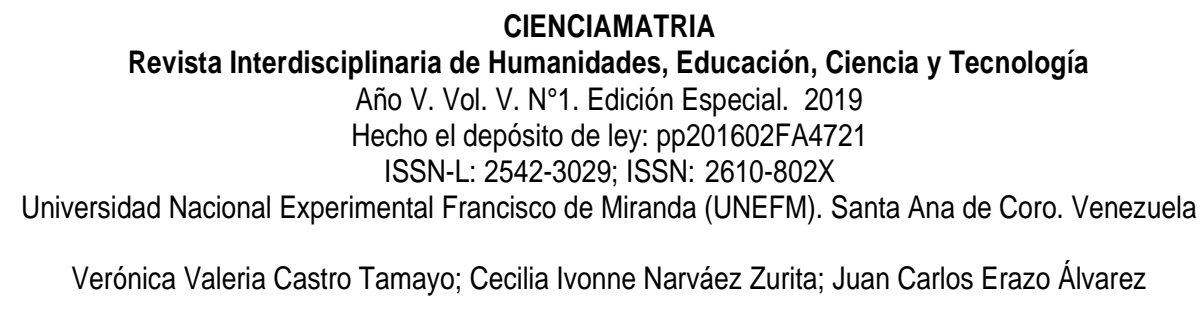

niño. Obtenido de http://ciifen.org/index.php

6. Córdoba, M. (2014). Análisis financiero. Bogotá: Ecoe ediciones.

7. Córdova, M. (2012). Gestión financiera. Bogotá: Ecoe Ediciones.

8. Chirinos, A. (2016). La innovación como factor clave de éxito en la gerencia de las empresas de producción social venezolana. CIENCIAMATRIA, 2(2), 97-106. https://doi.org/10.35381/cm.v2i2.55

9. Elbehri, A., c, Calberto, G., Staver, C., Hospido, A., Roibas , L., . . Bustamante, A. (2015). Cambio climático y sostenibilidad del banano en el Ecuador: Evaluación de impacto y directrices de política. Organización de las Naciones Unidas para la Alimentación y la Agricultura.

10. Eslava, J. (2010). Análisis económico - financiero de las decisiones de gestion empresarial. Madrid: ESIC Editorial.

11. García Colín, J. (2008). Contabilidad de costos. México: McGRAW-HILL/INTERAMERICANA EDITORES S.A. DE C.V.

12. García, J. (2014). Contabilidad de costos (Cuarta ed.). México: McGraw-Hill/Interamericana editores, S.A.

13. Grupo Intergubernamental de Expertos sobre el Cambio Climático (IPCC). (2007). Cambio climático 2007: impactos y vulnerabilidad. Cambridge University Press.

14. Iglesias, A., \& Medina, F. (2009). Consecuencias del cambio climático para la agricultura: ¿Un problema de hoy o del futuro? Revista Española de Estudios Agrosociales y Pesqueros (221), 45-70.

15. Laporta, R. (2016). Costos y gestión empresarial (Primera ed.). Bogotá: Ecoe Ediciones Ltda.

16. Meigs, R., Williams, J., Haka, S., \& Bettner, M. (2012). Contabilidad. La base para decisiones gerenciales. México: McGraw-Hill Companies.

17. Ministerio de Agricultura, Ganadería, Acuacultura y Pesca. (2014). Guía de buenas prácticas agrícolas para banano.

18. Molina, O. (2017). Rentabilidad de la producción agrícola desde la perspectiva de los costos reales: municipios Pueblo Llano y Rangel del estado Mérida, Venezuela. 


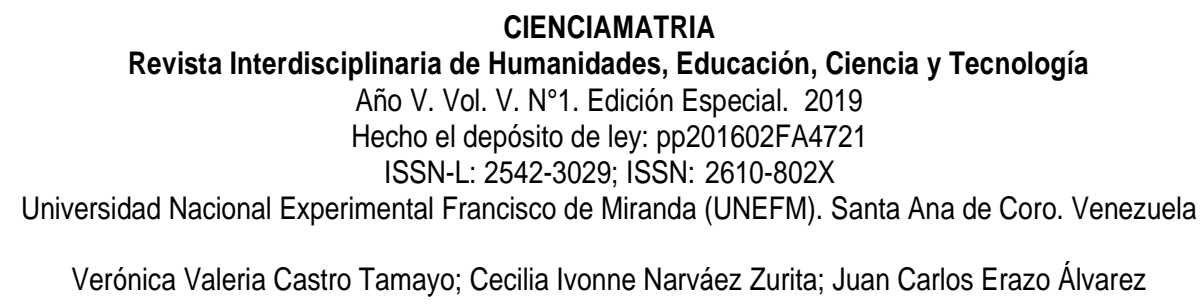

Vision Gerencial.

19. Moreno, J., Blanco, C., \& Mendoza, R. (junio de 2009). Buenas prácticas agrícolas en el cultivo de banano en la región del Magdalena. Medellín, Colombia: Comunicaciones Augura.

20. Ocampo, O. (2011). El cambio climático y su impacto en el agro. Revista de Ingeniería (33), 115-123. Obtenido de http://www.redalyc.org/articulo.oa?id=121022658012

21. Ortiz. (febrero de 2012). El cambio climático y la producción agrícola. Banco Interamericano de Desarrollo.

22. Ortiz, H. (2011). Análisis financiero aplicado y principios de administración financiera. Bogotá: Universidad Externado de Colombia.

23.PROECUADOR. (2016). Obtenido de https://www.proecuador.gob.ec/pubs/product-analysis-of-banana/

24. Rincón, C. (2009). Costos, decisiones empresariales. Bogotá: Ecoe Ediciones.

25. Rodríguez, L. (2012). Análisis de estados financieros. Un enfoque en la toma de decisiones. México: McGraw-Hill Interamericana.

26. Van Horne, J., \& Wachowicz, J. (2002). Fundamentos de Administración Financiera. México: Pearson Educación.

\section{REFERENCES CONSULTED}

1. Arredondo González, M. (2015). Accounting and Cost Analysis (2nd edition ed.). Mexico: Patria Editorial Group.

2. Arraiz, A. (2018). Framerwork of development of Sociotechnological Projects based on the notation of Metamodels of Software Engineering processes (spem 2.0). Interdisciplinary Arbitrated Review Koinonía, 3 (6), 79-95. Recovered from https://fundacionkoinonia.com.ve/ojs/index.php/revistakoinonia/article/view/141/121

3. Baena, D. (2010). Financial analysis. Bogotá: Ecoe Editions.

4. Bonsón, E., Cortijo, V., \& Flores, F. (2009). Financial statement analysis. Madrid: 


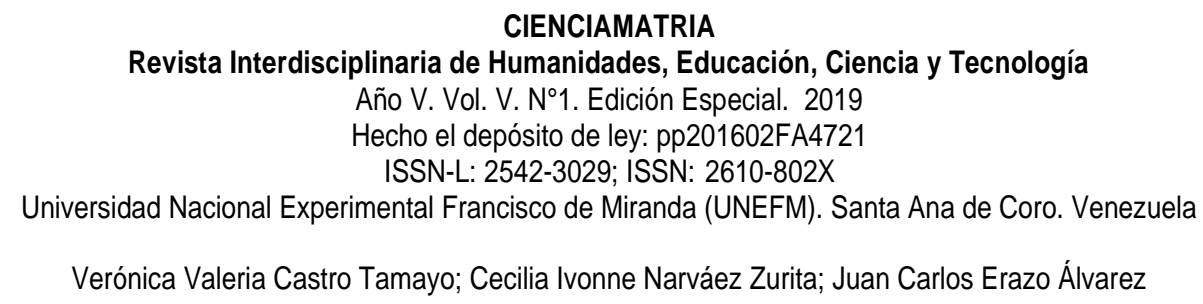

Pearson.

5. CIIFEN (2016). International Center for Phenomenon Research of El Niño. Retrieved from http://ciifen.org/index.php

6. Córdoba, M. (2014). Financial analysis. Bogotá: Ecoe editions.

7. Córdova, M. (2012). Financial management. Bogotá: Ecoe Editions.

8. Chirinos, A. (2016). Innovation as a key success factor in the management of Venezuelan social production companies. SCIENCE, 2 (2), 97-106. https://doi.org/10.35381/cm.v2i2.55

9. Elbehri, A., c, Calberto, G., Staver, C., Hospido, A., Roibas, L.,. . Bustamante, A. (2015). Climate change and sustainability of bananas in Ecuador: Impact assessment and policy guidelines. United Nations Food and Agriculture Organization.

10. Eslava, J. (2010). Economic - financial analysis of business management decisions. Madrid: ESIC Editorial.

11. García Colín, J. (2008). Cost accounting. Mexico: McGRAW-HILL / INTERAMERICANA EDITORES S.A. OF C.V.

12. García, J. (2014). Cost accounting (Fourth ed.). Mexico: McGraw-Hill / Interamericana editores, S.A.

13. Intergovernmental Panel on Climate Change (IPCC). (2007). Climate change 2007: impacts and vulnerability. Cambridge University Press.

14. Iglesias, A., \& Medina, F. (2009). Consequences of climate change for agriculture: A problem of today or of the future? Spanish Journal of Agrosocial and Fisheries Studies (221), 45-70.

15. Laporta, R. (2016). Costs and business management (First ed.). Bogotá: Ecoe Ediciones Ltda.

16. Meigs, R., Williams, J., Haka, S., \& Bettner, M. (2012). Accounting. The basis for management decisions. Mexico: McGraw-Hill Companies.

17. Ministry of Agriculture, Livestock, Aquaculture and Fisheries. (2014). Guide of good agricultural practices for banana. 


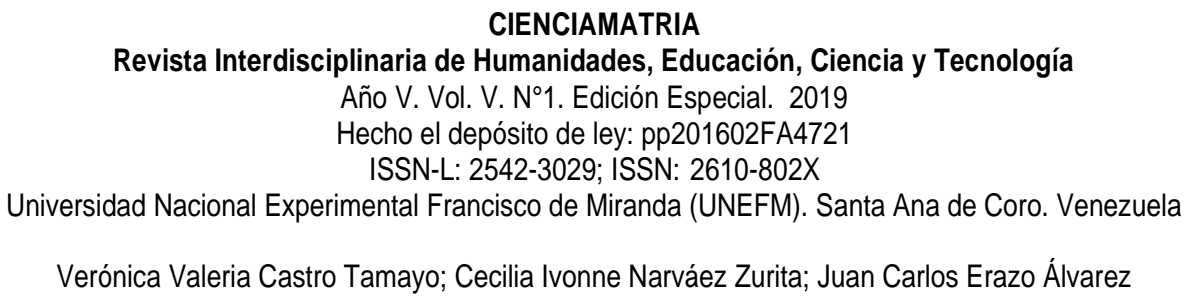

18. Molina, O. (2017). Profitability of agricultural production from the perspective of real costs: Pueblo Llano and Rangel municipalities in the state of Mérida, Venezuela. Management Vision

19. Moreno, J., Blanco, C., \& Mendoza, R. (June 2009). Good agricultural practices in banana cultivation in the Magdalena region. Medellin, Colombia: Augura Communications.

20. Ocampo, O. (2011). Climate change and its impact on agriculture. Engineering Magazine (33), 115-123. Retrieved from http://www.redalyc.org/articulo.oa?id=121022658012

21. Ortiz (February 2012). Climate change and agricultural production. Inter-American Development Bank.

22. Ortiz, H. (2011). Applied financial analysis and principles of financial administration. Bogotá: Externado University of Colombia.

23. PROECUADOR. (2016). Retrieved from https://www.proecuador.gob.ec/pubs/product-analysis-of-banana/

24. Rincon, C. (2009). Costs, business decisions. Bogotá: Ecoe Editions.

25. Rodríguez, L. (2012). Financial statement analysis. A focus on decision making. Mexico: McGraw-Hill Interamerican.

26. Van Horne, J., \& Wachowicz, J. (2002). Fundamentals of Financial Administration. Mexico: Pearson Education.

(C2019 por los autores. Este artículo es de acceso abierto y distribuido según los términos y condiciones de la licencia Creative Commons Atribución-NoComercial-Compartirlgual 4.0 Internacional (CC BY-NCSA 4.0) (https://creativecommons.org/licenses/by-nc-sa/4.0/). 